\title{
A Critique of Utilitarian Trust: The Case of the Dutch Insurance Sector
}

\author{
Erik van Rietschoten ${ }^{1}\left[\right.$. Koen van Bommel $^{1}$
}

Received: 21 January 2021 / Accepted: 13 January 2022 / Published online: 3 February 2022

(c) The Author(s) 2022

\begin{abstract}
The organizational trust literature relies strongly on the notion of trust and trustworthiness as a calculative cause-and-effect relationship aimed at assessing the advantages and disadvantages between two actors. This utilitarian notion of trust has been critiqued by studies that highlight construct inconsistencies related to utilitarian trust, which, it is argued, is deficient, incomplete and misleading. Our empirical study of the Dutch insurance sector identifies and categorizes three process inconsistencies that help to explain why the calculation of trust in a utilitarian sense is seemingly impossible in practice and is a barrier to the unambiguous assessment of individual needs and individual utility. These process inconsistencies successively concern insufficient information, complex behavioural dynamics, and a convoluted pattern of stakeholder influence to assess utility in trust relationships, specifically within complex socio-economic systems. Our findings contribute to the trust literature by proposing a classification of the previous critiques on utilitarian trust, and by showing that in scenarios of systematic rather than dyadic trust, process inconsistencies may be too strong to endure a 'leap of faith', at least with regard to suspension and assessing utilitarian trust in these more complex socio-economic systems.
\end{abstract}

Keywords Trust $\cdot$ Utilitarianism $\cdot$ Finance $\cdot$ Calculative trust $\cdot$ Insurance

\section{Introduction}

Trust, often defined as "the willingness of a party to be vulnerable to the actions of another party based on the expectations that the other will perform a particular action important to the trustor, irrespective of the ability to monitor or control that other party" (Mayer et al., 1995, p. 712) is a characteristic of well-functioning organizations and societies. Consider the example of the Dutch insurance sector, which, in the midst of the most recent financial crisis, was hit by a scandal around usury policies that led to radical public discontent and reduction in customer trust (Dutch Association of Insurers, 2016). In 2013, the Supreme Court of the Netherlands ruled that one of the leading insurers in the Netherlands had incorrectly charged costs as premium for a term life insurance, while these costs should have been administered

Erik van Rietschoten

erikjvanrietschoten@gmail.com; e.j.van.rietschoten@vu.nl

Koen van Bommel

k.van.bommel@vu.nl

1 School of Business and Economics, Vrije Universiteit Amsterdam, De Boelelaan 1105, 1081 HV Amsterdam, The Netherlands as savings deposit for policy holders. ${ }^{1}$ In the aftermath of the scandal, new regulations were introduced and insurers reorganized their processes in an attempt to restore order and regain customer trust (Dutch Association of Insurers, 2013). This only has resulted in a limited increase in the level of trust in that industry (DNB - Dutch National Bank, 2021).

Prior work has extensively studied organizational trust related to business activity. While different conceptualizations of trust exist, a form of cause-and-effect thinking with calculative interaction between two parties is central to most of this work. For instance, calculative trust indicates a perception of trust that is based on transaction cost economics and risks related to dependence "on the performance of another actor" (Williamson, 1993, p. 463). Cognitive trust is used to indicate "beliefs or expectations about others' trustworthiness" (Becker, 1996, p. 44). Calculus-based trust is understood as a form of trust that emerges "when the trustor perceives that the trustee intends to perform an action that is beneficial" (Rousseau et al., 1998, p. 399). Economic- and rational trust are terms used to perceive trust as a system of reasoning to deduce trust or trust related risks (Hollis, 1998). This is also understood as trust based on "rational choice theory" or "transaction cost economics" (Möllering,

${ }^{1}$ HR 14 June 2013 , ECLI:NL:PHR:2013:BZ3749 (art. 3.61). 
2001, p. 412). Transaction cost trust refers to a type of trust in which individuals act "to maximize expected gains or minimize expected losses from their transactions" (Rodgers, 2009, p. 86).

Despite their differences, what the above-mentioned notions of trust largely have in common is that they include a calculative interaction and a mutual assessment of the effect of one party's behaviour on the other party's trust. This assessment implicitly includes the weighing of particular (dis)advantage in trust relationships: the advantage to trust or to be regarded trustworthy (Mayer et al., 1995), and the disadvantage of experiencing betrayal or to be regarded untrustworthy (Elangovan \& Shapiro, 1998). Thinking in terms of cause-and-effect calculations of the trustee's trustworthiness to assess the trustor's risk of betrayal, has governed our understanding of organizational trust since the end of the last century, befitting a dominant neo-liberal, utilitarian-based economic society. Causal assessment of individual utility is thus perceived as paramount to trust relationships. To underscore the assessment of "risks and reward and with it, any purely utilitarian orientation and sense-making" to trust (Reich-Graefe, 2014, p. 67), for the purpose of this study we coin the term utilitarian trust to indicate the research tradition in which cause-and-effect deduction of individual utility is central. With utility we refer to a deliberately considered property that produces "benefit" and "advantage", or prevents the occurrence of "mischief" and disadvantage to a party "whose interest is considered" (Bentham, 2014, p. 2). We recognize a trustor's trust as the advantage, and a trustor's expected or experienced betrayal as the disadvantage involved.

The six trust approaches used in the extant literature, seem to be insufficient to explain the essential characteristic of deducing individual utility in trust relationships. The terms 'calculative', 'cognitive', 'calculus-based', 'rational', 'economic', or 'cost-transactional' are specifically used to indicate the nature of a trustor's assessment of a trustee's behaviour in order to deduce the trustor's advantage or disadvantage to trust. However, such assessment may also arise from altruistic instead of utilitarian motives, for example to determine how to support a trustee. While the terms used do suggest the fundamental 'what's-in-it-for-me' nature of deducing advantages or disadvantages to the trustor, they neglect to explicate it, which the term utilitarian trust exactly does and as such captures an essential feature of the trust conceptualizations discussed above. We therefore use the label utilitarian trust throughout this paper to capture this essential element of these trust approaches.

Literature on utilitarian trust typically focuses on causeand-effect assessment of individual utility in trust relationships between two actors. In practice, however, trust problems also arise in more complex (organizational) systems, for instance the Dutch insurance industry, with dynamic interactions over time involving multiple stakeholders. When utilitarian trust is considered as a systemic phenomenon, the system is a community of members involved and utility is regarded as "the sum of the interests of the several members who compose [that community]" (Bentham, 2014, p. 3). It appears that the utilitarian trust literature represents a view in which trust, as considered in the context of a system, is taken to be the sum total of trust that exists in all relationships within that system.

In the organizational trust literature, utilitarian trust is critiqued for two reasons. First, utilitarian trust is said to contain construct inconsistencies, arguing it to be deficient (Darley, 1998), incomplete (Cohen \& Dienhart, 2013; Flores \& Solomon, 1998; Hollis, 1998) and misleading (Becker, 1996; Williamson, 1993). Second, literature on utilitarian trust is argued to contain process inconsistencies, specifically with regard to the process of assessing whether or not the utilitarian 'expectation' that underlies trust is 'favourable' or 'unfavourable' (Möllering, 2001). Cost-benefit analyses are typically difficult to manage as trust involves a degree of uncertainty that expectations will be met, which necessitates a 'leap of faith' (Flores \& Solomon, 1998; Möllering, 2001). Möllering (2001) argues that 'suspension' is needed to enable this leap of faith to trust and thus circumvent the process inconsistency. Drawing on Giddens (1991), suspension is a "mechanism that brackets out uncertainty and ignorance, thus making interpretative knowledge momentarily 'certain' and enabling the leap to favourable (or unfavourable) expectation" (Möllering, 2001).

To date, the exact nature and how to cope with utilitarian trust's process inconsistencies has remained largely theoretical. Empirically, we know little about how a leap of faith and suspension as enablers of trust function in practice. This is particularly salient as most studies have taken a more personal or relational dyadic perspective to trust while we know enduring leaps of faith and establishing trust depends on given circumstances (Flores \& Solomon, 1998) and varies "according to the situation" (Möllering, 2001, p. 406). Therefore, we ask the question whether managing process inconsistencies to trust also applies to a more complex trust system with its combination of various societal, economic and personal interests (Möllering, 2001). We know this more systemic notion of trust differs from personal trust, also referred to as relational trust (Rousseau et al., 1998) or dyadic trust (Korsgaard et al., 2015). Consequently, the research question of our study is "How do process inconsistencies complicate assessment of utilitarian trust in socioeconomic systems?".

We focus our case study on the Dutch insurance industry that we view as a complex socio-economic setting with a multitude of stakeholders, interest and demands. Our article contributes to the trust literature by explicating the notion of utilitarian trust and by going beyond the existing construct 
inconsistencies of utilitarian trust (Flores \& Solomon, 1998; Williamson, 1993) and instead gain further insight into the process inconsistencies (Möllering, 2001) to assess individual utility in trust relationships. We extend and categorize these process inconsistencies and show these are not only an accidental 'course of nature' but may be consciously created for utilitarian considerations. Our empirical focus on a case in which trust is a systemic rather than dyadic phenomenon (Korsgaard et al., 2015; Mayer et al., 1995) reveals that process inconsistencies can under such circumstances make assessing individual utility close to impossible, which complicates the (re)building of trust in a utilitarian sense.

The article is organized as follows. First, we describe utilitarian trust theory and categorize work critiquing utilitarian trust. Second, the methods section describes the specific case of the Dutch insurance sector and our study design, data collection and analysis methods. The next section presents our findings, which are discussed in the final section along with some implications for the literature on organizational trust and professional practice, and suggestions for future research.

\section{Theoretical Framework}

\section{Origins of Utilitarian Trust}

Mayer et al.'s (1995) definition of trust was a milestone in this literature because it integrated a range of previous trust studies within a single organizational trust model. The model includes a trustor, who trusts, and a trustee, who is to be trusted, and includes causal dependencies between the antecedents to trust and trustworthiness. Mayer et al.'s (1995) work led to a stream of research in this tradition that further refined utilitarian trust. These studies aim, primarily, to understand the relationship between trustor and trustee and explain how this relationship contributes to the utility of one of the parties, usually the trustor. They typically discuss this relationship from four perspectives: (1) by quantifying the interactions within the relationship; (2) investigating the mutual influence of the antecedents to the relationship; (3) examining the calculative nature of that influence; and (4) identifying the actors involved in this mutual influence. First, while Mayer et al. (1995) refer only to a 'feedback loop' and the constant returns to trust, Bhattacharya et al., (1998, p. 463) mathematically substantiate the relationship and its consequences in terms of "outcomes that are favourable to a person". Second, Castaldo et al. (2010) categorize trust in terms of mutual dependent antecedents to trust, based on an automated content analysis of the trust literature. Third, in terms of the calculative nature of the relational dynamics involved, Harrison et al. (1998) focus on the origins of trust relationships while Lewicki et al. (1998) integrate levels of trust and distrust as the social reality within these relationships. Sheppard and Sherman (1998) examine relational interdependence in trust and Lewicki et al. (2006) investigate how trust relationships develop. Fourth, Fulmer and Gelfland (2012) discuss the types of actors-individuals, teams and organizations-involved in trust relationships.

\section{Utility and Utilitarian Trust}

The main characteristic of utilitarian trust is the causality between the antecedents to trust which maximize the utility of the trust relationship. Specifically, trustworthiness defines the trustor's expected utility in terms of the level of trust or the chances of a breach of trust. Central to these studies is the relationship between trustor and trustee and the trustee's actions and character. Trustee actions refer to general behaviour and specific terminology and decisions (Bhattacharya et al., 1998; Lewicki et al., 1998). Trustee character refers to the trustee's competence and predictability (Harrison et al., 1998) or honesty (Castaldo et al., 2010), or the trustee's ability, benevolence and integrity (Mayer et al., 1995). These studies suggest that the trustee's actions or character lead to a positive result for the trustor, described as trust, whose meaning and content-related utility for the trustor differ across studies. The utility resulting from trustworthiness is defined as the expectation that the trustor will "perform a particular action important to the trustor" (Mayer et al., 1995, p. 712), which leads to "positive or non-negative outcome" (Bhattacharya et al., 1998, p. 462), to "hope" (Caldwell et al., 2008, p. 104), or to "positive results" (Castaldo et al., 2010, pp. 665-666).

\section{Empirical Findings for Utilitarian Trust}

In the utilitarian trust tradition, there are numerous (mostly quantitative) empirical studies examining the relation between trust and utility. The work in this stream typically assesses trust deductively by measuring the causality between trust and ability, benevolence and integrity, as antecedents to trustworthiness suggested by Mayer et al. (1995). Most of this work tends to be people-focused or businessfocused. People related trust studies add to our understanding of how much trust mediates risk in stakeholder relations (Caldwell \& Karri, 2005; Greenwood \& Van Buren Iii, 2010; Ryan \& Buchholtz, 2001), interactions with customers (Leonidou et al., 2012; Tsai et al., 2015) and employees' performance (Caldwell \& Clapham, 2003; Duane Hansen et al., 2015; Holtz, 2013). The stream of business related trust studies contribute to better understanding of the extent to which trust mediates brand perception (Castaldo et al., 2008; Kang \& Hustvedt, 2013; Singh et al., 2012), team performance (De Jong \& Elfring, 2010; Krishnan et al., 2006; Langfred, 2007; Luo, 2001), leadership (Chughtai 
et al., 2015; Lleó de Nalda et al., 2016; Newman et al., 2013; Schaubroeck et al., 2013) and ethical behaviour (Colquitt \& Rodell, 2011; Trapp, 2011).

\section{Critiques of Utilitarian Trust}

Critiques of utilitarian trust are primarily conceptual and are somewhat fragmented. Critiques of utilitarian trust may be categorized into construct inconsistencies, indicating that the extant explanation of the phenomenon does not grasp its supposed purpose, and process inconsistencies, indicating defaulting assessments of utility in trust relationships.

\section{Construct Inconsistencies of Utilitarian Trust}

Critique is fragmented and more prominent within the business ethics literature rather than the management literature. Our analysis suggests that work on utilitarian trust is deficient, incomplete and misleading.

The criticism that utilitarian trust is deficient refers to the fact that maximizing individual utility ignores the need for growing trust and commitment among the parties involved: "Trust deepens and moves from a deal-maker's trust to the more committed kind" (Darley et al., 1998, p. 322). Also, utilitarian or self-interested trust underestimates the view of trust as contributing to the organization's morals (Jones \& Bowie, 1998) and suggests a greater probability of corruption (Husted, 1998).

The incompleteness of utilitarian trust refers to the absence of intrinsic motivators. For example, Hardin (1996, p. 28) argues that "our strongest commitments are often merely those that are clearly backed by our interests". Also, rational economic accounts of trust necessarily focus on the individual risk of breach of trust, which, consequently, deprives trust of its inherent collective prosperity (Hollis, 1998). In addition, the causally dependent utility of trust lacks explicit acceptance of trust and interprets breach of trust as the unexpected action of the trustee, rather than a morally undesirable action (Cohen \& Dienhart, 2013).

The misleading nature of utilitarian trust refers to a sense of trust where no trust exists. Flores and Solomon (1998) argue that trust as a tool to achieve efficiency can be interpreted as inauthentic or phony and lead to distrust. In addition, the expectation of utility for one or more of the parties, might be due to cronyism and societal bias rather than pursuit of collective benefit for a larger group or all of society (Koehn, 1996). Williamson (1993) emphasizes the societal perspective and considers that calculative, utilitarian trust results in inconsiderate economic actions caused by opportunism and economic consequences that are too extensive to comprehend arithmetically. Understanding trust as a cause-and-effect phenomenon to deduce the trustor's benefit in dyadic trust may be tempting for its simplicity, as Becker (1996) argues, but hard to pin down within vast economic organization.

\section{Process Inconsistencies of Utilitarian Trust}

Moreover, in addition to construct inconsistencies utilitarian trust is also critiqued on being subject to process inconsistencies. That is, there are inconsistencies with regard to the process of establishing utility in trust. In the extant literature we observe two process inconsistencies, one of which has been accepted as preconditional to trust, although it is not clear whether this applies to all circumstances, while the other is as yet mostly a theoretical suggestion.

First, it has been accepted in trust theory that trust must involve a certain degree of uncertainty, as full certainty eliminates the need for trust. More precisely, for maximum return and utility, ideally any trustee's free will to behave in certain ways should be contractually restricted (Flores \& Solomon, 1998), while full knowledge of future trustee behaviour should be present (Möllering, 2001), and any uncertainty about this behaviour should be eliminated (Reich-Graefe, 2014). However, since such guarantees do not exist in free socio-economic environments, it is said that trust and trustworthiness should arise from free will (Flores \& Solomon, 1998), that 'weak inductive knowledge' in trust relationships is inevitable (Möllering, 2001), and that uncertainty is insurmountable in relationships of trust (Reich-Graefe, 2014). Consequently, the tolerated process inconsistency referred to, concerns a so-called 'leap of faith' to trust (Flores \& Solomon, 1998; Möllering, 2001), which bridges the lack of certain knowledge in trust relationships (Möllering, 2001, p. 405) and harmonizes expected utility with awareness of uncertainty (Reich-Graefe, 2014, p. 72).

Second, in utilitarian trust theory, it is suggested that the understanding of trust misses the notion of suspension (Möllering, 2001). 'Suspension' refers to bridging the time between the emergence of an expectation of (un)favorable outcomes and the moment certainty emerges whether the expectation will be met. 'Weak inductive knowledge' necessitates a leap of faith. In trust, suspension mediates (un) favourable expectation and the leap of faith, "thus making interpretative knowledge momentarily 'certain"' (Möllering, 2001, p. 414).

Today, the understanding of the 'leap of faith' and 'suspension' with regard to interpretations of (un)favourable expectations of trust is theoretical, yet requires "more specific [...] conceptual and empirical" research (Möllering, 2001, p. 417). A 'leap of faith', for example, is said to be "riddled with 'given' circumstances" (Flores \& Solomon, 1998, p. 228) and to vary "according to the situation" (Möllering, 2001, p. 406). Hence, we don't know how the existing process inconsistencies of assessing trust in a utilitarian sense works in practice, nor whether the inconsistencies described 
apply to all contexts. While they may apply to relatively simple personal or dyadic trust relationships, whether managing process consistencies as described above, while remaining utilitarian, still works in more complex socio-economic systems with a history of broken trust remains to be seen. For example, governments' disproportionate liberalization of regulation in financial industries (Crespo \& Van Staveren, 2011) facilitated irresponsible behaviour of insurers, insurance advisors, and customers. This has exposed the interplay of at least four participants in a socio-economic system, not just two, leading to a global trust crisis in insurances. "A proper mixture of other-interested and self-interested behavior" is said to lead to "trust between individuals and cooperation within society" (Hosmer, 1995, p. 398). We wonder not just whether maximizing individual utility contributes to this 'proper mixture' in the insurance industry, but also whether pursuing this in a complex industry allows for a 'leap of faith'. With our study, we consider a particular case of high complexity, such as the Dutch insurance sector, to which suspension is crucial, which represents the time between issuing an insurance policy and the moment of compensation of an insurance claim, or payment of an insured sum.

\section{Methodology}

\section{Research Design}

To date, there are very few empirical examinations of critiques of utilitarian trust. Our explorative study of the limitations to a utilitarian trust approach uses inductive qualitative interviews with individuals in the insurance sector which has had severe trust-related problems since the financial crisis. We employ inductive analysis using grounded theory methods to provide in-depth empirical results based on finegrained data on utilitarian trust.

\section{Case Selection: Research Site}

During the most recent global financial crisis, it became apparent that life insurance companies were applying costs to term life insurances without the policyholders' knowledge. At the same time, insurers were proposing unrealistically high returns on underlying investments. This led to a national insurance scandal and, ultimately, a ruling by the Supreme Court of the Netherlands in favour of the policyholders in the case of one of the leading Dutch insurers. ${ }^{2}$ The Dutch insurance sector lost trust and was forced to introduce comprehensive measures to restore trust. We chose the case of the Dutch insurance sector because of its history of

\footnotetext{
$\overline{2}$ HR 14 June 2013, ECLI:NL:PHR:2013:BZ3749.
}

distrust and related efforts and investments to restore trust. These efforts are related mainly to the concept of utilitarian trust.

\section{Consequences of Distrust and Measures to Restore Trust}

The measures implemented to restore trust included compensation for unjustly high premiums for the risk of premature death within unit-linked insurances (Kifid, 2008) and reorganization of the sector. For instance, an expert Financial Services Complaints Institute was established to deal with complaints from individual customers, entrepreneurs and self-employed individuals (Kifid, 2020). Also, the recurring commissions being charged for certain products were cancelled and insurers were forced to be transparent about the commissions they were offering insurance advisors for certain products (AFM, 2017). The Dutch Association of Insurers also implemented a recovery programme to align insurers' actions and moral awareness to customers' interests (Dutch Association of Insurers, 2013). Most of these measures were utilitarian-based and were related to legislation, institutional compliance, supervision, codes of conduct and quality marks, intended to restore customer trust.

However, trust in the insurance sector has never fully recovered as shown by our analysis of the Dutch insurance sector. Dutch National Bank (2021) research shows that trust in the insurance sector dropped from $81 \%$ in 2006 to $56 \%$ in 2009 and only relatively increased to $68 \%$ in 2019. In 2009, the Dutch Association of Insurers (2016) estimated that while trust in the Dutch economy has significantly improved, customer distrust against insurers remains stubbornly high.

What is striking about the measures taken to restore trust, is that insurers' actions in particular were put central. The measures were aimed mainly at revising insurers' actions and moral behaviour, based on estimates of actions and behaviour that might increase trust. This cause-and-effect expectation of (dis)advantages in trust relationships is characteristic of utilitarian trust, where the trustee calculates the actions that lead to trustworthiness and the trustor assesses how much they engender trust from the trustor. Our interviews show that there was a desire to restore trust amongst participants in the Dutch insurance sector, yet for the most part participants were forced, by law, to adjust their behaviour to increase trust and individual utility. However, it is unclear whether this utility materialized and whether the associated behaviour was intrinsically motivated and genuine. Despite utilitarian measures to restore trust, the Dutch insurance industry continues to have trust related problems which is the reason for us to further scrutinize currently known process inconsistencies of utilitarian trust in a complex system. 
Table 1 Anonymized list of interviewees

\begin{tabular}{lllll}
\hline ID & $\begin{array}{l}\text { Type of actor representing } \\
\text { the insurance sector }\end{array}$ & $\begin{array}{l}\text { Overarching body or } \\
\text { participant }\end{array}$ & Position in organization & $\begin{array}{l}\text { Duration } \\
\text { of inter- } \\
\text { view }\end{array}$ \\
\hline S01 & Insurer & Overarching & Director & 1.10 .14 \\
S02 & Regulator & Overarching & Policy officer & 54.56 \\
S03 & Regulator & Overarching & Director & 56.10 \\
S04 & Insurer & Participant & Director & 53.42 \\
S05 & Insurer & Participant & Director & 47.50 \\
S06 & Regulator & Overarching & Policy officer & 46.23 \\
S07 & Insurer & Participant & Policy officer & 37.30 \\
S08 & Regulator & Overarching & Director & 38.44 \\
S09 & Insurer & Participant & Commissioner & 35.07 \\
S10 & Customers & Overarching & Director & 1.06 .44 \\
S11 & Advisors & Overarching & Director & 43.55 \\
S12 & Customers & Overarching & Policy officer & 46.28 \\
S13 & Insurer & Overarching & General director & 58.27 \\
S14 & Insurer & Participant & Head of Department & 1.18 .29 \\
S15 & Customers & Participant & Customer & 38.39 \\
S16 & Customers & Overarching & Policy officer & 1.03 .18 \\
S17 & Customers & Overarching & Director & 1.04 .22 \\
\hline & & & &
\end{tabular}

\section{Data Collection}

The Dutch insurance sector includes four main actors: customers, insurers, advisors and regulators. We collected data during 2015 to 2019 from these main actors. To identify interviewees, we first made a careful reading of industry documents and drew on the insider knowledge of the first author, who had professional experience in the industry. We used the snowball method to identify additional interviewees. Most of the organizations responded positively and many proposed executives as interviewees. We also interviewed selected employees to reduce latent management bias.

\section{Interview Strategy}

Our interviews were semi-structured and explored our research objectives while allowing interviewees to interpret our interview questions and objectives (Corbin \& Strauss, 2015). To link the interviews with the research context, interviews were held at interviewees' workplaces. We conducted 17 interviews with four regulators, seven insurers, one insurance advisor and five insurance customers before reaching saturation (Corbin \& Strauss, 2015). These interviews yielded sufficient insights to allow inferences about the deficiencies related to utilitarian trust. Our informants either represented an organization or an individual company and held various positions including CEO, general manager, head of department and policy officer. Table 1 presents the interviewees. The interviews were face-to-face and lasted $60 \mathrm{~min}$ on average, ranging from 30 to $90 \mathrm{~min}$. Interviews were double-recorded and were transcribed using the intelligent verbatim method, omitting ums, laughter and pauses. Interviews were transcribed by the researcher to enhance engagement with the data and to optimize the conditions for inductive analysis of our data. In one case, a transcription service was used (the service was required to sign a confidentiality agreement). All interviewees were guaranteed anonymity and were given the opportunity to validate the interview transcripts. In most cases, the only changes requested were changing to spellings/typos.

\section{Interview Questions}

The interviews were aimed at conceptual clarity and the questions were designed to explore interviewees' understanding of trust in the insurance sector and any problems or challenges resulting from this understanding (Kvale \& Brinkman, 2009). We did not ask directly about the deficiencies or process inconsistencies related to utilitarian trust since we considered this to be too abstract a concept. Instead, we selected a case where a utilitarian approach towards trust dominated, and asked our informants about their understanding of trust. We also asked about the origins of the current trust problems in their industry and specific trust characteristics that were neither calculative nor utilitarian in nature. 


\section{Additional Data}

We collected additional data (Corbin \& Strauss, 2015) on ongoing trust-related discussions within the Dutch insurance sector, based on reading professional journals and weekly newsletters. We also included data through observations of the first author, an insurance industry professional. These additional data contributed to a richer understanding of the study phenomenon.

\section{Data Analysis}

Our data analysis uses the grounded theory methods proposed by Glaser and Strauss (1967). First, to interpret the informants' experience and observation (Van Maanen, 1979), we explored our data to understand what our informants perceived to be deficiencies in the currently dominant approach to (re)building trust in the Dutch insurance sector. We constructed a group of first order data which we open coded (Corbin \& Strauss, 2015; Corley \& Gioia, 2004). We then categorized these first order codes into emerging themes that represent the opportunities we identified to contribute to the trust literature (Gioia et al., 2012). These second order or axial codes (Corbin \& Strauss, 2015; Corley \& Gioia, 2004) allowed further aggregation (Corley \& Gioia, 2004) to obtain insights into dominant process inconsistencies of utilitarian trust. Figure 1 presents the results of the data analysis.

\section{Researcher Bias}

One of the researchers pursues a career in the insurance sector. To maintain objectivity and independence, the study was financed by the authors' personal resources. The professional experience of the researcher may have been advantageous in terms of easier access to data. We tried to maintain objectivity, but cannot rule out some element of researcher bias. However, since the second author had no links to the insurance industry and was able to offer a distanced perspective, we believe that any possible bias has been overcome.

\section{Findings}

The Dutch insurance industry includes multiple stakeholders. On the one hand, we see customers with a relatively limited understanding of complex insurance products. On the other hand, there are providers of insurance products who are familiar with this complexity and use jargon understandable, mostly, only by these professionals. The insurance professionals include not only providers of insurance products, but also insurance advisors and regulators who, in some cases, are former insurance specialists. The result is an emerging dichotomy between the 'clueless customer' and the 'educated elite', which hinders cooperation and invites pursuit of individual utility, distinctive to utilitarian trust.

Both parties understand the importance of trust in the industry and the need to regain trust as shown by the following extract: "Trust can of course [mean] financial soundness. But I think that it is more ... about serving the real customer interest. I think people sometimes have their doubts about that. Insurers are simply viewed very suspiciously. And I think that is due to many different causes" [S05.001]. ${ }^{3}$ Parties do not cooperate, but work to build trust from their individual positions. Customers sue for compensation for the damage they believe has been incurred and have a negative image of insurers. Insurers try to bring their actions more in line with customers' interests, but also pursue their own interests as indicated by the high returns they achieve.

The pursuit of individual utility in trust relationships, which is a pivotal feature of utilitarian trust, remains dominant. As discussed above, the literature suggests that the pursuit of utilitarian trust leads to deficient, incomplete and misleading results. Our analysis shows that pursuit of utilitarian trust and its underlying principle of individual utility, is extremely difficult, if not impossible, when considering more complex trust relations of many actors and an interplay of self- and common interests. That is, the process underpinning utilitarian trust and its related cause-and-effect thinking and required leap of faith becomes problematic. First, the individual actor in a contemporary organization has insufficient information to assess individual utility. Second, the complicated behavioural dynamics in the relationships among the involved actors hinders assessment of individual utility. Third, there is an convoluted pattern of stakeholders influencing trust, making it too complicated to unambiguously derive individual utility. Table 2 presents the data.

\section{Insufficient Information to Assess Individual Utility}

One of the premises of trustworthiness is that the trustee has integrity and is benevolent and aims to do good to the trustor (Mayer et al., 1995). However, our analysis shows that trustees withhold information and falsely appear as a person of integrity and benevolence, leaving the trustor unable to objectively assess trustworthiness. Assessing the personal benefits and individual utility relative to another party requires knowledge about the actions, character and behaviour of both parties. We identified three reasons why participants in trust relationships cannot

\footnotetext{
3 We coded our quotes according to their interviewee and code number. In this case, interviewee S05 was related to code number 1.
} 


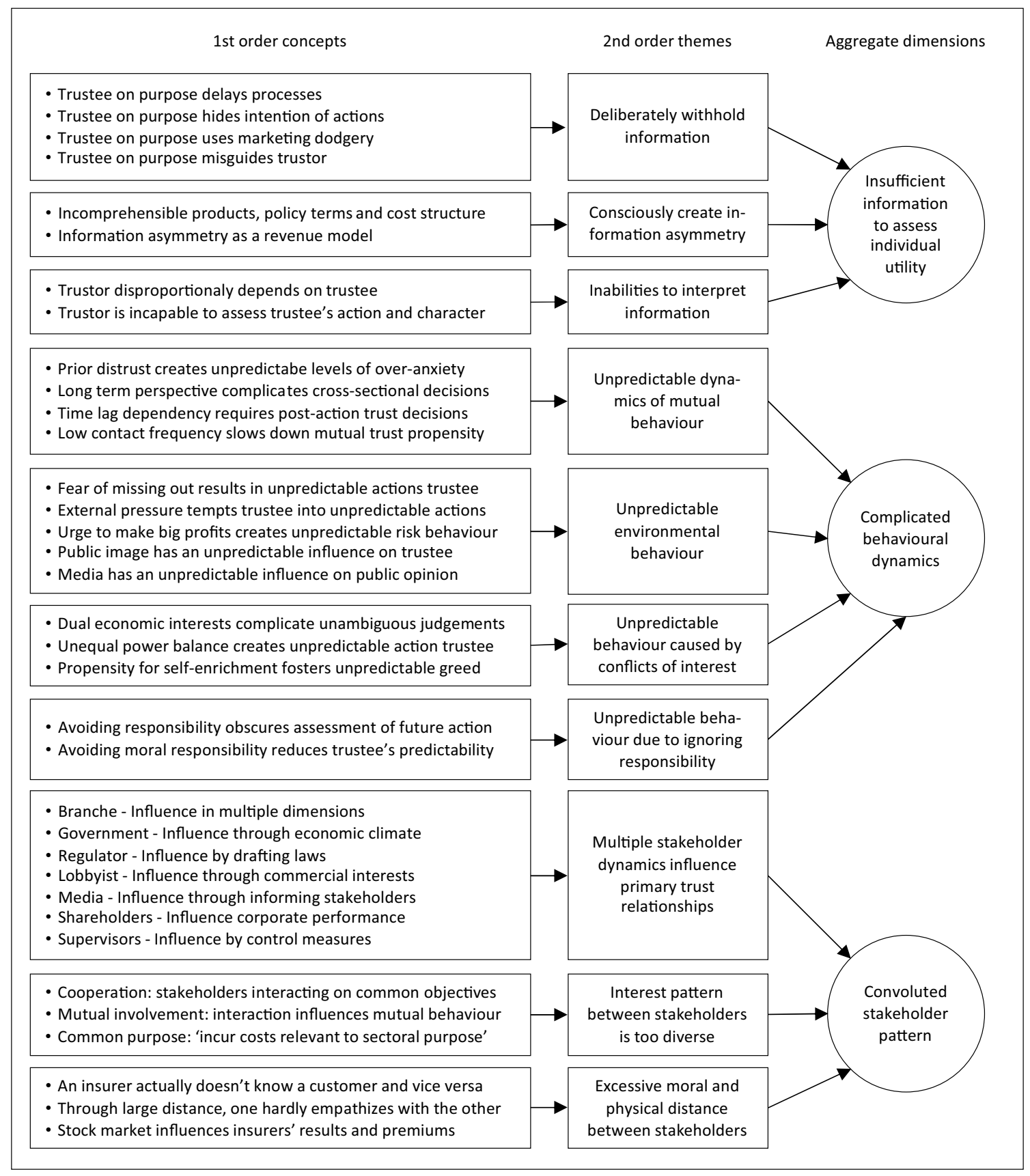

Fig. 1 Data structure: inconsistencies of utilitarian trust

assume that they have complete information to assess individual utility, or not even sufficient information to enable a leap of trust. First, participants in a trust relationship can deliberately withhold information. Second, participants can consciously create information asymmetries. Third, participants may have unequal ability to collect the necessary information.

\section{Deliberately Withholding Information}

While in trust relationships individual utility is specified by assessment of the trustee's trustworthiness, we found that trustees can deliberately withhold information, aimed, specifically, at misleading the trustor. In the insurance industry, this withholding of information can apply to both insurance 


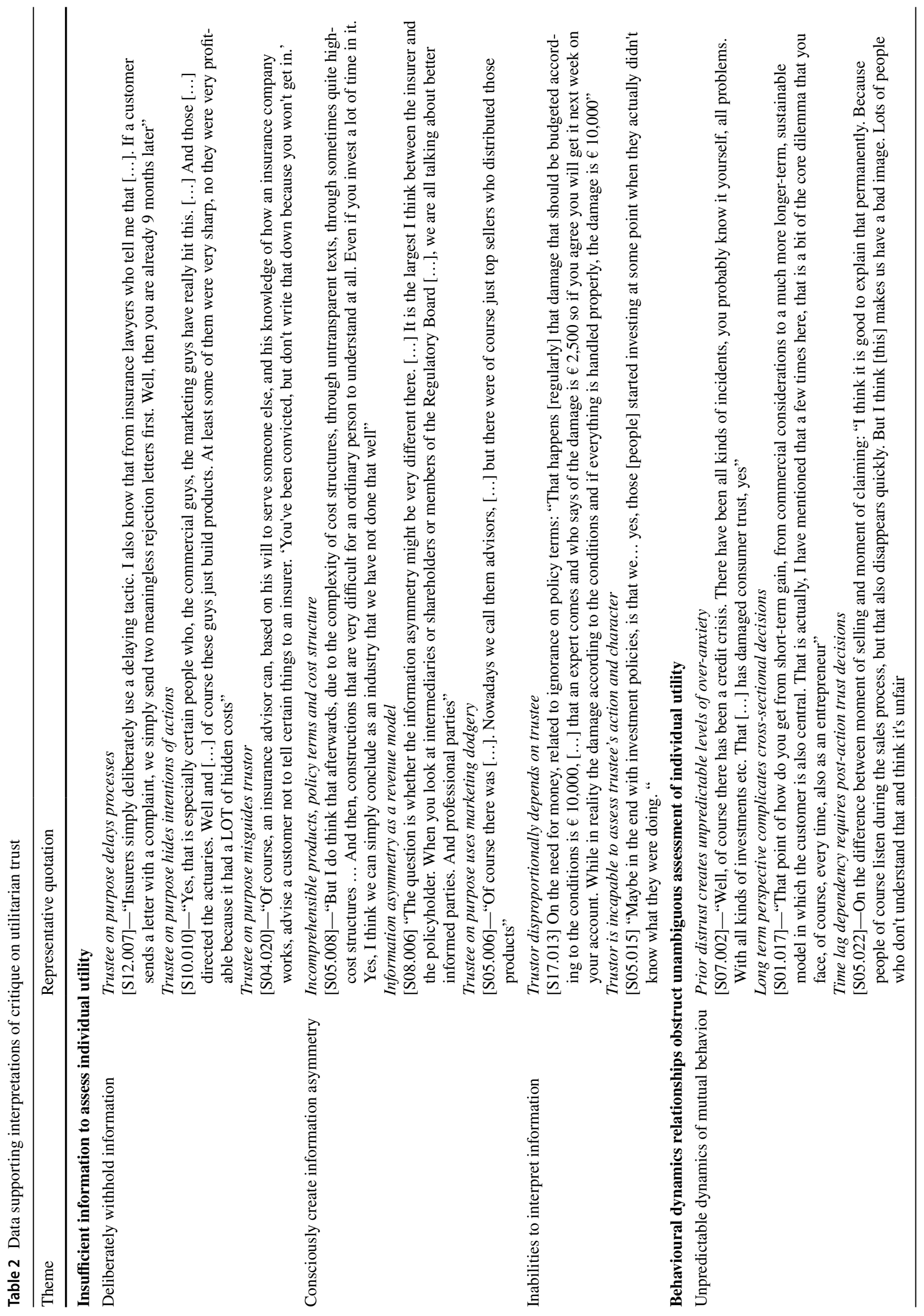




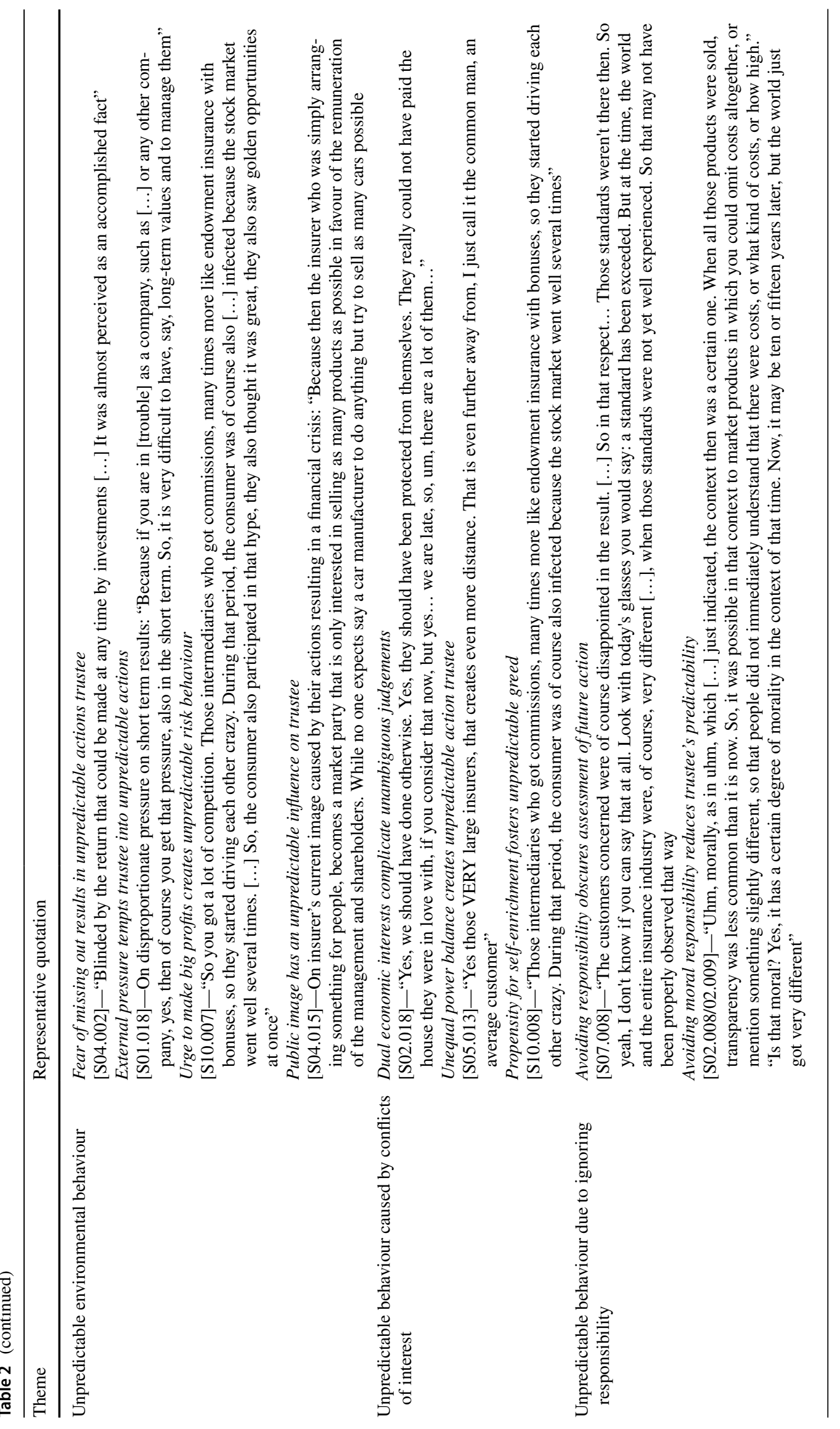




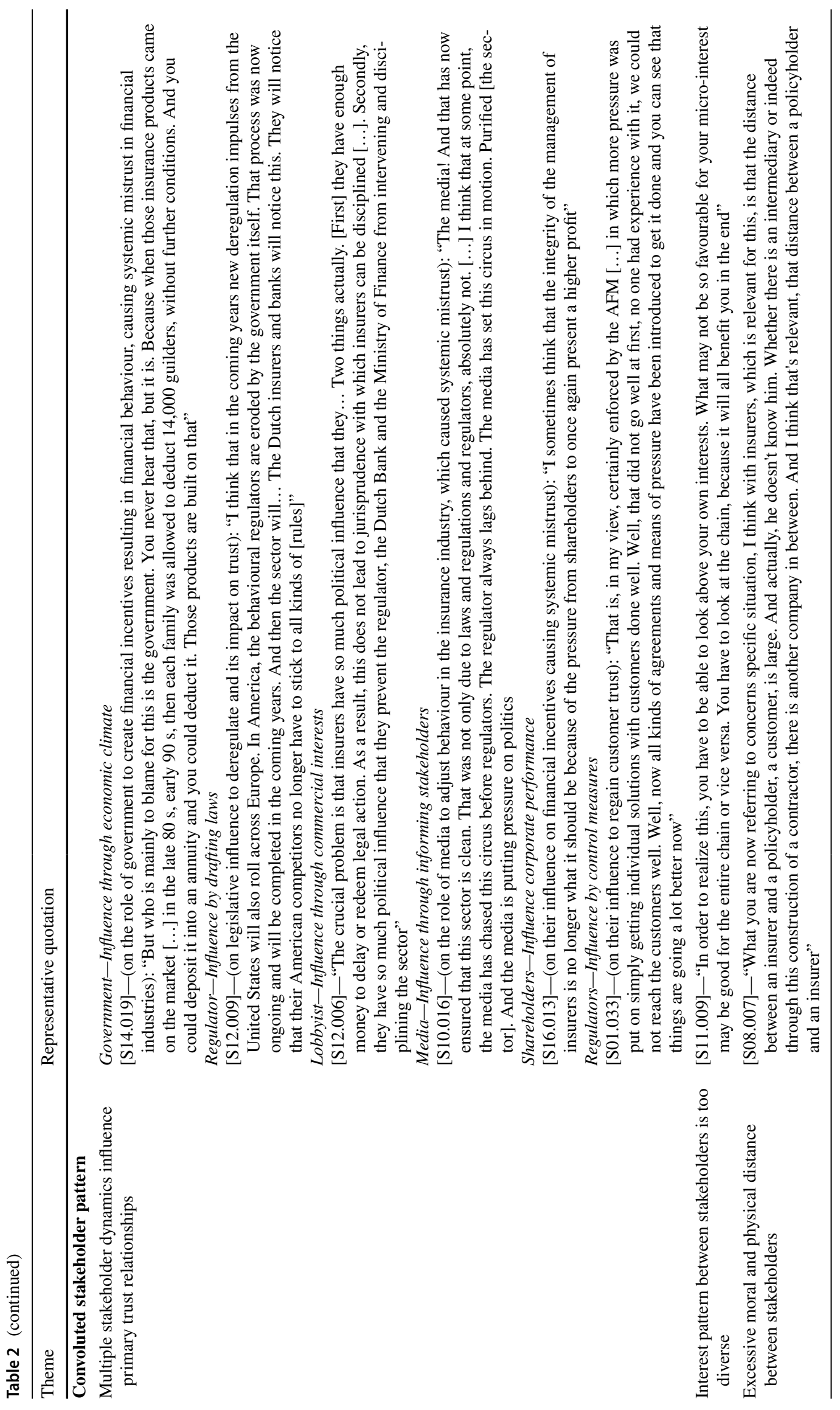


providers and customers. Providers may deprive customers of information by slowing the process or concealing excessive conditions. Our data suggest that slow administrative processes provide financial benefits for the insurer. A regulator told us that: "So, the moment you manage to postpone two claims on such a policy for half a year, you simply gained interest, so to speak" [S06.007]. In addition, another example of deliberately withholding information in trust relationships arises from the Dutch usury policy affair. Life insurers were specifically known as organizations that predicted excessively high investment profits for customers and administered some of their savings premiums as costs in their records. ${ }^{4}$ The problem occurring here is that customers are deprived of crucial information that is relevant to the relationship of trust. Conversely, the same thing happens in the trust relationship between customers and insurers. Customers may conceal potentially adverse circumstances when purchasing insurance or submitting insurance claims, leaving the insurer having to assess the risk and damage compensation, based on incomplete or false information.

\section{Consciously Creating Information Asymmetry}

We observed institutionalized and taken-for-granted practices that cause information asymmetry, resulting in the trustor having insufficient information to assess individual utility in a trust relationship. For example, in the insurance industry it is accepted that insurance products, policy terms and cost structures are couched in terms that make them difficult for the insured person to understand, which raises what some consider to be a deliberately created trust problem. A customer interviewee referred to disproportionate incentives derived from the insurers' revenue model "based on a difference of information and knowledge between them and the insurance customer" [S12.018]. Marketing efforts can also induce information asymmetry between trustor and trustee. An insurance customer recalled an insurance agent "who pretended to advise in the best interest of customers, but was in fact the insurers' sales representative" [S12.014].

\section{Inabilities to Interpret Information}

We observed situations where trustors were unable to value the trustee's actions due to insufficient information to assess individual utility of the trust relationship or the disproportionate dependence of the trustor on the trustee. Insurers tend to be wealthier than their customers, which creates inequalities for customers who depend on insurance benefits as critical income. Problems related to interpreting critical information about insurance products, cost structures and

\footnotetext{
$\overline{{ }^{4} \text { HR } 14 \text { June }}$ 2013, ECLI:NL:PHR:2013:BZ3749.
}

policy terms, leave trustors unable to assess trustworthiness. An insurer described the resulting distrust by directly linking the complexity of policy terms to customers' perception that insurers do not trust them: "If you look at the policy conditions ..., I think if [customers] read those conditions, they experience us as not trusting them, at least" [S06.014]. Another observation clearly shows how agreements in the insurance sector that necessitate long-term trust illustrate the phenomenon of 'suspension'. On the time interval of possibly several decades between purchasing insurance and receiving an insurer's decision to not pay out a customer's claim, it is said that a customer may have forgotten the information about insurance coverage received at the time of purchase. "Of course people listen during the sales process, but that disappears quickly. I think [rejecting a claim may unjustly] give [insurers] a bad image" [S05.022]. Apart from the fact that it is often no longer possible to verify what information the insured has received at the time of sale, this example clearly shows that a 'leap' of several decades to validate the reasons for trust might be too large. Especially when potentially significant financial interests are taken into account.

\section{Complicated Behavioural Dynamics}

We found that complicated behavioural dynamics further hinder unambiguous assessment of individual needs and individual utility. Both trustor and trustee behaviours may change continuously, as do their interactions and contextual environment. These changes are unstructured, which makes unambiguous assessment of trustworthiness and its utility difficult. While prior work may have suggested such patterns before, we find that in particular in a complex system such as the insurance industry these different dynamics to be irreconcilable. We found four behavioural dynamics that complicate assessment of individual utility in trust relationships. First, the dynamics between participants has an unpredictable impact on trust relationships. Second, the trust relation environment is unpredictable. Third, conflicts of interest in the trust relationship result in unpredictable behaviour. Fourth, if one of the participants does not assume its responsibilities, the behaviour of other participants in a trust relationships becomes unpredictable.

\section{Unpredictable Behaviour Dynamics}

Unambiguous assessment of individual utility in a trust relationships depends on the behaviour of the participants. Their behaviour could change constantly, making this behaviour dynamic, which makes it difficult to deduce personal benefit. First, prior distrust causes uncertainty about trusting the participant in the future. An insurance customer told us 
that: "Insurers half-heartedly acknowledged [their fault in the usury policy affair] and compensated inadequately ..., which caused mistrust. And that has not been removed to a large extent" [S12.005]. Second, the long-term relationships and the time-lags between actions and expected outcomes complicate assessment of individual utility. This applies particularly to the insurance sector because actions that validate trustworthiness, such as satisfying claims or making pensions payments, can occur a long time after the insurance policy has been taken out. A regulator told us that: "Customers pay their premiums, but when they need an insurer and claim any damage, the insurer will not pay out anyway and they will find a way to avoid payment. That's the image of insurers" [S02.007]. Third, frequency of contact between trustor and trustee can affect assessment of trustworthiness. Infrequent contact results in lack of relevant information. The regulator told us that: "There is little conversation with an insurer, because it's at remote distance, and there's often an intermediary in between. Moreover, there is very few, or absent contact" [S08.011].

\section{Unpredictable Environmental Behaviour}

We identified three environmental characteristics that interact with assessment of individual utility in trust relationships and ultimately hinder suspension enabling a leap of faith towards trust. Peer influence can influence calculation of individual utility and can damage primary trust relationships. First, role-affirming behaviour can lead to unethical actions, such as the offer of products developed prior to the financial crisis. An insurer argued that moral responsibility for the development of life insurance packages with investment risks was influenced by environmental incentives. "So, if you have a government that supports investing through insurances with tax facilities, and you as company A [for moral reasons] consider not selling this, your competitor will" [S04.014]. Second, socio-economic trends, confirmed or encouraged by peers, can influence assessment of individual utility and obscure underlying moral values and common trust principles. A regulator argued: "Insurers told advisors: 'do not ask how it is possible, but take advantage'. ... It would be foolish to not participate in this race" [S02.013]. "It was almost like... gosh, you just have to participate .... Otherwise, you will miss [all the financial opportunities]" [S03.009]. Finally, media and reputation have an effect on assessment of individual utility in trust relationships. They can prolong negative perception of an insurer that has implemented measures to change behaviour or can trigger behavioural change. A customer referred to the media exposure of the usury policy affair in the Netherlands: "Well, the media! [...] The media has set [behavioural corrective actions] in motion $[\ldots]$ and put pressure on politics" [S10.018].

\section{Unpredictable Behaviour Caused by Conflicts of Interest}

In trust relations, conflicts of interest among the participants can cause unpredictable behaviour that complicates objective assessment of individual utility in trust. This is one thing when it happens in relatively simple relational or dyadic trust relations, but in more complex trust systems (i.e. the insurance industry) it becomes even more difficult. First, diverging economic interests may result in economic asymmetry between participants, which lead to uncertainty about how the trust actions of the counterparty should be valued. A customer noted that: "Yes, they make good money from insurance, so to speak. It is not that I say 'great, they are very service-orientated'. And it does fall in the serviceorientated sector, right? Does it?" [S15.005]. Second, unequal power enables dominance of one of the parties, which obstructs assessment of individual utility in trust. An insurer suggested that "[a rejected claim] can easily be interpreted as unjust. The buildings [insurers] hold office in, the cars they drive in, they are not getting smaller. It feels like a mismatch" [S04.017]. Finally, if there is a propensity for excessive self-enrichment in the trust relation, unambiguous assessment of individual utility decreases. Customers can be accused of "obtaining financial benefit by cheating their insurer" [S09.002] by submitting overly high or false claims. Insurance advisers may try to sell insurance policies with a particular insurer because of the higher commission they will receive [S11.006].

\section{Unpredictable Behaviour Due to Ignoring Responsibility}

Some insurers took no responsibility for past actions, arguing that their behaviour was related to the particular circumstances in place at the time. Whether this abdication of responsibility is conscious or unconscious, if no responsibility is taken for past action, this makes it impossible for the actors to assess individual utility in future trust actions. Several interviewees suggested that potential lack of moral responsibility in the past constitutes a legitimate argument for denying responsibility in the present. However, if actors morally reject certain behaviour, but do not take responsibility when they have displayed that behaviour themselves, their future behaviour becomes unpredictable, which complicates assessments of individual utility in trust relationships. A regulator told us: "Looking back, can you blame an individual insurer? ... Consumers were happy [with those insurance products], and as a company you make a profit. Can you blame someone for that" [S03.010]? And: "The usury policy affair, which triggered a considerable crisis of trust, you could discuss whether it was a conscious choice 
or not. What we think is [morally] normal today does not equate with what was accepted years ago" [S03.003].

\section{Convoluted Stakeholder Pattern}

While the primary trust relationship in the insurance sector is between insurer and customer, and most trust measures are aimed at that relationship, various other stakeholders also play an important role and influence the trust relationship. Intentionally or unintentionally, these stakeholders influence the primary trust relationship, although whether the actors in the relationship are aware of this influence is unknown. This opaque pattern of stakeholder influence on trust relationships further complicates objective and unambiguous assessment of individual utility in trust relationships in three ways. First, numerous stakeholders are involved. Second, the interests of these external stakeholders and their interest in the primary trust relationship, make it difficult to manage trust. Third, potentially excessive moral or physical distance add further complications.

\section{Multiple Stakeholder Dynamics Influence Primary Trust Relationships}

Without exception, mistrust in the insurance sector is considered the result of insurers' behaviour prior to and after the financial crisis. When asked about trust, informants, at first, use a dyadic account of trust and, when talking about trust, refer to the relationship between insurers and customers and ignore, either consciously or unconsciously, the more complex systemic rather than dyadic nature of trust within their industry. However, while none of our interviewees made this connection, they did suggest that there are various actors that influence the trust relations. For example, governments promulgate laws and regulations governing relationships, which require legal knowledge to assess individual utility in the primary trust relationship. The participants' actions are controlled by regulators and customer organizations that publish rules which add complexity. Lobbyists influence government and the regulator, which can affect insurance products and, thus, assessment of individual utility in the primary trust relationship. Shareholders who are influenced by financial returns, also influence insurers' behaviours, which makes it more difficult for the customer to assess individual utility. Typically, external stakeholders influence both the individual utility of stakeholders involved in the primary trust relationship and their personal utility. As a regulator told us: "The insurance industry is all about money, which flows from customers to insurers, and in case of some events flows back. Well, where there is money, is my personal conviction, there is sometimes an incentive .... This industry probably attracts people who want to take advantage" [S02.028]. This sector may indeed be all about money. Through this quote we observe that the assessment of individual utility, in this case financial utility, is particularly complicated when multiple stakeholders influence this assessment, such as in the insurance industry.

\section{Interest Pattern Between Stakeholders is Too Diverse}

In addition to individual interests, there are common interests that are pursued in utilitarian trust relationships, which affect assessment of individual utility in trust relationships. A customer told us that: "If an insurer develops a product, let them have a group of customers who explain them their strengths and weaknesses in the social field" [S16.016]. This suggestion to collaborate is at odds with the utilitarian principle to assess individual utility in trust relationships. Another inconsistency to pursuing individual utility, is evident from the involvement of actors in the insurance sector, who work together to solve various problems related to the increasing use of digital data. An insurer told us that: "I think we need to keep in mind that data use should be for the right purpose and that its use should serve insurance rather than destroy it by increasingly extracting the good from the bad risks" [S13.010]. Amongst pursuing individual benefits, participants in the insurance sector clearly experience additional common goals. The diverse individual and common interests add further complexity to assessment of individual utility.

\section{Excessive Moral and Physical Distance Between Stakeholders}

The moral and physical distance between stakeholders complicates assessment of individual utility in trust relationships. Individual customers see themselves as insignificant actors in primary trust relationships in the insurance sector, due to the sector's impersonal nature, and insurers' large expensive offices. Although insurance advisors should engage with customers, an insurer told us that the physical and moral distance between insurers and customers cause them to "hardly empathize with the other person" [S05.012]. The physical distance means that the parties do not know one another and the moral distance makes the customer feel his or her interests are not recognized.

\section{Discussion}

This study sets out to further progress the organizational trust literature, in particular by offering an empirical illustration of how process inconsistencies complicate assessment of utilitarian trust in socio-economic systems. We examined 
the case of the Dutch insurance sector to challenge the idea of trust as a cause-and-effect relation, specifically aimed at deducing individual utility of either of the parties involved. Our analysis highlights that the process of assessing utilitarian trust is hampered by a lack of information, the complex behavioural dynamics in relationships and the convoluted stakeholder patterns. While some of these process inconsistencies may have been raised before, we do not only systematically categorize them, but also show that in cases of complex socio-economic trust systems (i.e. a form of systemic trust that is set against more dyadic or relational ones), the identified process consistencies may fundamentally hamper the assessment of individual utility in trust relationships, highlighting the limits of utilitarian trust.

These results resonate with and extend prior literature that discusses process consistencies of utilitarian trust. It speaks to previous accounts of a lack of definite knowledge about a trustee's expected behavior, which necessitates the issue of trust in the first place. Some have suggested to counter this by highlighting the importance of 'suspension', indicating a fixed period of uncertainty from the moment trust emerges until the moment of recognized actual knowledge about the favourable or unfavourable outcome of trust (Möllering, 2001), thereby enabling a 'leap of faith' (Flores \& Solomon, 1998; Möllering, 2001). While our analysis recognizes the relevance of these concepts, at the same time we question whether a leap of faith can actually be managed when confronted with systemic trust within more complex socio-economic systems.

Our analysis highlights three central process inconsistencies related to assessing utilitarian trust in socio-economic systems, which suggests the difficulty of deducing utilitarian trust under human conditions. To perform an objective and unambiguous calculation of individual utility in trust would require an unmanageable number of dependent variables whose value would be difficult to estimate. Parties in trust relationships may have insufficient information available to assess individual utility in trust, which on the one hand may have been intentionally caused by the trustee and which, on the other hand, may not be interpretable due to a trustor not being competent to do so. Behavioural dynamics add a further complication to assess individual utility in trust as does the opaque pattern of the stakeholders involved. As said, this affects both the 'leap of faith' and the notion of 'suspension'.

That is, consciously created information asymmetries, inabilities to interpret information, complicated behavioural dynamics, and convoluted stakeholder patterns in our insurance industry case are extensively incorporated into the system, while the interests of all stakeholders involved are significantly large. As a result, the 'leap of faith' that forms part of assessing individual utility is compromised and essentially becomes too uncertain to make. Similarly, Möllerings (2001, p. 403) notion of suspension as "the mechanism of bracketing the unknowable" and an important facet of assessing utility becomes problematic as well. Indeed, the notion of suspension is vital to trust, as without suspension, there would be immediate certainty whether an expectation will be met, eliminating the need for trust. In that sense, the notion of suspension indeed 'enables' trust. But that is not to say it makes the process of assessment of individual utility in trust any easier, quite the contrary, as is evident in our case. In the insurance industry, for example, 'suspension' may extend for a lifetime in the case of term life insurance, where trust is 'suspended' from the moment the insurance is taken out until the time the insurer should pay out due to an insured's decease.

However, while term life insurances may be unique to the insurance industry, we argue that the notion that suspension may add to the complexity of assessing individual utility could be relevant also to cases beyond the insurance industry. Suspending certainty as to whether trust is justified is fairly straightforward if both duration of suspension and the interests involved are reasonable, but process-wise opaque and risky otherwise, at least if the assessment of individual utility is central. Examples outside the insurance industry abound, such as the process to transfer real estate property, which is usually reduced to a specific time for transfer involving notarial and legal intervention. Moreover, within larger organizational systems, multiple trust relationships subsist between various stakeholders such as employees, consumers, civil society, shareholders, and all within a complex and changing environment. While we have studied the insurance industry specifically, our case also addresses a broader issue in which trust not only occurs between two equal individuals. Rather, trust is a phenomenon inherent to cluttered complex socio-economic systems in which a specific individual is unable to assess utility against comprehensive public and governmental institutions. In complex socioeconomic systems, the sum total of process inconsistencies may endanger rather than enable 'the leap' to favourable (or unfavourable) expectation. This builds further on work (e.g. Flores \& Solomon, 1998; Möllering, 2001) that asked the question whether notions of leap of faith and suspension indeed hold under all circumstances and contexts.

In business, trust problems are not confined to dyadic relationships (i.e. personal or relational trust), but occur in contexts where environmental factors play a vital part. In our study context, these involve the trust relationship between insurer and customer, which takes place in the context of the insurance sector, among different types of participants, and in the context of history. Context and history related to the relationship are often overlooked in work on utilitarian trust. Mayer et al. (1995) allude to this by considering the role of context and long-term effects as complicating objective assessment of trust. However, they do not go into detail, but instead refer to a 'feedback loop' where calculations of 
trust are repeated based on the same cause-and-effect protocol. However, in the insurance industry issues around time, long-term effects and delays are an emblematic feature of the nature of the industry. Assuming utilitarian trust and the underlying condition of individual utility in trust relationships, means that analysis of a simple trust problem requires multiple data and can be so time consuming as to be infeasible.

Our findings support conceptual questioning of the current understanding of utilitarian trust. While it is possible for utilitarian trust in an organizational context to result in actual trust, we argue this is not straightforward. Since utilitarian behaviour arouses suspicion, the calculative nature of the cause-and-effect relationship between trust and trustworthiness increases the contradictions among the parties, while trust suggests a certain rapprochement and mutual interest. Also, the relational approach between trustor and trustee has some limitations. The existing literature shows an unequal relationship between trustor and trustee, in which the trustee has discretionary powers and the trustor is mainly vulnerable (K. Jones, 1996; Mayer et al., 1995). However, this inequality only occurs in the hypothetical situation of trust being a non-reciprocal phenomenon in which a party calculates trustworthiness of another party. In practice, this hypothetical situation never occurs, because it includes both calculations of trust by the trustor and trustee's calculation of how to act in order to be trusted. Calculative assessments of trust are not single non-reciprocal events leading to an overall trust decision in terms of utility to either of the two participants in the relationship, nor are they a consecutive series of recurring events as suggested by Mayer et al. (1995). Rather they are a set of complex events over time, leading to trust among multiple participants in a socio-economic system, whose mutual interaction has an effect on the shared trust in that system. Overall, we seek to make three central contributions to the literature with these findings. First, we extend the literature by highlighting the procedural mechanisms to assess utility in trust and, by building on Möllerings (2001) suggestion of 'suspension', introduce the notion of process inconsistencies of utilitarian trust. In particular we systematically categorize three process inconsistencies that obstruct assessment of individual utility: insufficient information, complicated behavioural dynamics and convoluted stakeholder patterns. Second, yet related, we further build on the literature on utilitarian trust by empirically showing that this type of trust may work well for more dyadic, personal or relational trust relations (Korsgaard et al., 2015; Mayer et al., 1995), yet possibly less so for more complex systemic types of trust relations. The process inconsistencies in such contexts may become too powerful to overcome, and a 'leap of trust' (Flores \& Solomon, 1998; Möllering, 2001) impossible to endure. Third, by introducing 'utilitarian trust' we offer a useful overarching analytical label to cause-and-effect theories related to a concept of organizational trust focused on an assessment of the (dis)advantages of trust (Bhattacharya et al., 1998; Mayer et al., 1995).

\section{Practical Implications}

Much financial and other investment have been made to regain customer trust in the Dutch insurance sector. Trust as part of insurance sector organizational activity is important in all countries. Further attempts to restore long term trust services should show that the economy needs a flourishing insurance sector, given the financial risks involved, and a flourishing insurance sector based on trust will reduce the costs of compliance with legislation, codes of conduct and quality marks. This should decrease transaction costs and the cost of insurance premiums. By a flourishing insurance sector, we do not mean a profitable sector, but rather a sector that provides value to the customer. The current problems in the insurance sector require a different research lens. We suggest two approaches to restoring trust and measuring trust.

Current efforts are aimed at adjusting the behaviour of insurers, in the expectation that this will induce customer trust. Our study of utilitarian trust suggests some reconsideration of the relational approach, its calculative characteristics and the level of analysis. First, we show that trust is not a relational phenomenon related to how one must act to create trust in another. Second, we show that the utilitarian and calculative nature of trust relationships should be reconsidered as they lead to opposite positions within a relationship. The parties are unlikely to be confident about trustworthiness which is imposed by regulation; they may instead act in their own interests. Third, we suggest that trust should be considered a system phenomenon. Further research could focus on the system level. However, this would suggest the need for a critical look at the core principles of the system and not just the relationships between buyers and suppliers.

\section{Limitations and Future Research}

The present study contains some limitations and also offers several directions for future research. First, focusing on one specific case always leaves the question of generalizability to contexts other than, in our case, the insurance industry. Utilitarian trust could therefore be studied in different contexts to examine the existence of construct and process inconsistencies or provide different insights, which might improve our conceptual understanding of utilitarian trust and its deficiencies. Second, while our study highlights the problematic nature of utilitarian trust by identifying process inconsistencies, it does not provide a full-blown alternative to utilitarian trust. Future studies could take a normative approach to trust and further explore the inherent moral 
values by focussing on long term trust in a complex multiple actor society. Such research could focus on the moral conditions in socio-economic systems under which an equilibrium between the pursuit of self and common interests emerges, and thus contributes to trust in complex organizational systems. Third, the theoretical perspectives of utilitarian trust on the one hand, and more normative aspects of trust on the other, may be linked in constructive dialogue with the aim of contriving an understanding of trust that meets the empirical challenges of contemporary socio-economic industries.

Funding Both authors did not receive support from any organization for the submitted work. No funding was received to assist with the preparation of this manuscript. No funding was received for conducting this study. No funds, grants, or other support was received.

\section{Declarations}

Conflict of interest Employment Erik van Rietschoten is employed by an insurance firm. Financial interests To avoid appearance of conflict of interest, Erik van Rietschoten took initiative to renounce the employer's regular study costs reimbursement scheme for his doctoral studies and then financed this study from personal resources. Nonfinancial interests The professional experience of the researcher may have been advantageous in terms of easier access to data. We tried to maintain objectivity, but cannot rule out some element of researcher bias. However, since the second author had no links to the insurance industry and was able to offer a distanced perspective, we believe that any possible bias has been overcome. Koen van Bommel has neither conflicts of interest to declare that are relevant to the content of this article, nor relevant financial or non-financial interests to disclose.

Open Access This article is licensed under a Creative Commons Attribution 4.0 International License, which permits use, sharing, adaptation, distribution and reproduction in any medium or format, as long as you give appropriate credit to the original author(s) and the source, provide a link to the Creative Commons licence, and indicate if changes were made. The images or other third party material in this article are included in the article's Creative Commons licence, unless indicated otherwise in a credit line to the material. If material is not included in the article's Creative Commons licence and your intended use is not permitted by statutory regulation or exceeds the permitted use, you will need to obtain permission directly from the copyright holder. To view a copy of this licence, visit http://creativecommons.org/licenses/by/4.0/.

\section{References}

AFM. (2017). Ban on commission. Retrieved from https://www.afm. nl/nl-nl/professionals/doelgroepen/adviseurs-bemiddelaars/belon ing/provisieverbod

Becker, L. C. (1996). Trust as noncognitive security about motives. Ethics, 107, 43-61.

Bentham, J. (2014). An Introduction to the Principles of Morals and Legislation. Dover Publications Inc.

Bhattacharya, R., Devinney, T. M., \& Pilluta, M. M. (1998). A formal model of trust based on outcomes. Academy of Management Review, 23(3), 459-472.
Caldwell, C., \& Clapham, S. E. (2003). Organizational Trustworthiness- An International Perspective. Journal of Buiness Ethics, 47, 349-364.

Caldwell, C., Davis, B., \& Devine, J. A. (2008). Trust, faith, and betrayal: Insights from management for the wise believer. Journal of Business Ethics, 84(S1), 103-114. https://doi.org/10.1007/ s10551-008-9689-0

Caldwell, C., \& Karri, R. (2005). Organizational governance and ethical systems-A covenantal approach to building trust. Journal of Business Ethics, 58, 249-259.

Castaldo, S., Perrini, F., Misani, N., \& Tencati, A. (2008). The missing link between corporate social responsibility and consumer trust: The case of fair trade products. Journal of Business Ethics, 84(1), 1-15. https://doi.org/10.1007/s10551-008-9669-4

Castaldo, S., Premazzi, K., \& Zerbini, F. (2010). The meaning(s) of trust. A content analysis on the diverse conceptualizations of trust in scholarly research on business relationships. Journal of Business Ethics, 96(4), 657-668. https://doi.org/10.1007/ s10551-010-0491-4

Chughtai, A., Byrne, M., \& Flood, B. (2015). Linking ethical leadership to employee well-being: The role of trust in supervisor. Journal of Business Ethics, 128(3), 653-663. https://doi.org/10. 1007/s10551-014-2126-7

Cohen, M. A., \& Dienhart, J. (2013). Moral and amoral conceptions of trust, with an application in organizational ethics. Journal of Business Ethics, 112(1), 1-13. https://doi.org/10.1007/ s10551-012-1218-5

Colquitt, J. A., \& Rodell, J. B. (2011). Justice, trust, and trustworthiness: A longitudinal analysis integrating three theoretical perspectives. Academy of Management Journal, 54(6), 1183-1206. https://doi.org/10.5465/amj.2007.0572

Corbin, J., \& Strauss, A. L. (2015). Basics of Qualitative Research (4th ed.). Sage Publications Inc.

Corley, K., \& Gioia, D. A. (2004). Identity ambiguity and change in the wake of a corporate spin-off. Administrative Science Quarterly, 49(2), 173-208.

Crespo, R. F., \& Van Staveren, I. (2011). Would we have had this crisis if women had been running the financial sector? Journal of Sustainable Finance \& Investment, 1(3-4), 241-250. https://doi. org/10.1080/20430795.2012.655892

Darley, J. (1998). Trust in organizations: Frontiers of theory and research. Business Ethics Quarterly, 8(2), 319. https://doi.org/ $10.2307 / 3857331$

Darley, J., Kramer, R., \& Tyler, T. (1998). Trust in organizations: Frontiers of theory and research. Business Ethics Quarterly, 8(2), 319. https://doi.org/10.2307/3857331

De Jong, B. A., \& Elfring, T. (2010). How does trust affect the performance of ongoing teams? The mediating role of reflexivity, monitoring, and effort. Academy of Management Journal, 53(3), 535-549.

DNB - Dutch National Bank. (2021). Public trust in financial institutions. Retrieved from https://www.dnb.nl/actueel/algemeennieuws/dnbulletin-2021/vertrouwen-in-financiele-sector-overe ind-in-coronacrisis/

Duane Hansen, S., Dunford, B. B., Alge, B. J., \& Jackson, C. L. (2015). Corporate social responsibility, ethical leadership, and trust propensity: A multi-experience model of perceived ethical climate. Journal of Business Ethics, 137(4), 649-662. https://doi.org/10. 1007/s10551-015-2745-7

Dutch Association of Insurers. (2013). Routekaart VerzekeraarsVernieuwen.

Dutch Association of Insurers. (2016). Customer trust in insurers. Retrieved from

Elangovan, A. R., \& Shapiro, D. L. (1998). Betrayal of trust in organizations. Academy of Management Review, 23(3), 547-566. 
Flores, F., \& Solomon, R. C. (1998). Creating trust. Business Ethics Quarterly, 8(2), 205-232. https://doi.org/10.2307/3857326

Fulmer, A. C., \& Gelfland, M. J. (2012). At what level (and in whom) we trust-Trust across multiple organizational levels. Journal of Management, 38(4), 1167-1230.

Giddens, A. (1991). Modernity and self-identity. Polity Press.

Gioia, D. A., Corley, K. G., \& Hamilton, A. L. (2012). Seeking qualitative rigor in inductive research-Notes on the Gioia methodology. Organizational Research Methods, 16(1), 15-31.

Glaser, B. G., \& Strauss, A. L. (1967). The Discovery of Grounded Theory, Strategies for Qualitative Research.

Greenwood, M., \& Van Buren Iii, H. J. (2010). Trust and stakeholder theory: Trustworthiness in the organisation-stakeholder relationship. Journal of Business Ethics, 95(3), 425-438. https://doi.org/ 10.1007/s10551-010-0414-4

Hardin, R. (1996). Trustworthiness. Ethics, 107, 26-42.

Harrison, M. D., Cummings, L. L., \& Chervany, N. L. (1998). Initial trust formation in new organizational relationships. Academy of Management Review, 23(3), 474-490.

Hollis, M. (1998). Trust within reason. Cambridge University Press.

Holtz, B. C. (2013). Trust primacy. Journal of Management, 39(7), 1891-1923. https://doi.org/10.1177/0149206312471392

Hosmer, L. T. (1995). Trust-The connecting link between organizational theory and philosophical ethics. Academy of Management Review, 20(2), 379-403.

Husted, B. W. (1998). The ethical limits of trust in business relations. Business Ethics Quarterly, 8(2), 233-248. https://doi.org/10.2307/ 3857327

Jones, K. (1996). Trust as an affective attitude. Chicago Journals, 107(1), 4-25.

Jones, T. M., \& Bowie, N. E. (1998). Moral hazards on the road to the “virtual” corporation. Business Ethics Quarterly, 8(2), 273-292. https://doi.org/10.2307/3857329

Kang, J., \& Hustvedt, G. (2013). Building trust between consumers and corporations: The role of consumer perceptions of transparency and social responsibility. Journal of Business Ethics, 125(2), 253-265. https://doi.org/10.1007/s10551-013-1916-7

Kifid. (2020). About Kifid. Retrieved from https://www.kifid.nl/ over-kifid/

Kifid. (2008). Aanbeveling ombudsman: kosten beleggingsverzekeringen maximeren, deels consument compenseren [Press release]

Koehn, D. (1996). Should we trust in trust. American Business Law Journal, 34, 183-203.

Korsgaard, M. A., Brower, H. H., \& Lester, S. W. (2015). It isn't always mutual-a critical review of dyadic trust. Journal of Management, 41(1), 47-70.

Krishnan, R., Martin, X., \& Noorderhaven, N. G. (2006). When does trust matter to alliance performance? Academy of Management Journal, 49(5), 894-917.

Kvale, S., \& Brinkman, S. (2009). InterViews; Learning the Craft of Qualitative Research Interviewing (2nd ed.). SAGE Publications Inc.

Langfred, C. W. (2007). The downside of self-management- A longitudinal study of the effects of conflict on trust, autonomy, and task interdependence in self-managing teams. Academy of Management Journal, 50(4), 885-900.

Leonidou, L. C., Kvasova, O., Leonidou, C. N., \& Chari, S. (2012). Business unethicality as an impediment to consumer trust: The moderating role of demographic and cultural characteristics. Journal of Business Ethics, 112(3), 397-415. https://doi.org/10.1007/ s10551-012-1267-9

Lewicki, R. J., McAllister, D. J., \& Bies, R. J. (1998). Trust and distrust-New relationships and realities. Academy of Management Review, 23(3), 438-458.

Lewicki, R. J., Tomlinson, E. C., \& Gillespie, N. (2006). Models of interpersonal trust development: Theoretical approaches, empirical evidence, and future directions. Journal of Management, 32(6), 991-1022. https://doi.org/10.1177/0149206306 294405

Lleó de Nalda, Á., Guillén, M., \& Gil Pechuán, I. (2016). The influence of ability, benevolence, and integrity in trust between managers and subordinates: The role of ethical reasoning. Business Ethics: A European Review, 25(4), 556-576. https://doi.org/10.1111/beer. 12117

Luo, Y. (2001). Building trust in cross-cultural collaborations- Toward a contingency perspective. Journal of Management, 28(5), 69694.

Mayer, R. C., Davis, J. H., \& Schoorman, F. D. (1995). An integration model of organizational trust. Academy of Management Review, 20(3), 709-734.

Möllering, G. (2001). the nature of trust-From Georg Simmel to a theory of expectation. Interpretation and Suspension. Sociology, $35(2), 403-420$

Newman, A., Kiazad, K., Miao, Q., \& Cooper, B. (2013). Examining the cognitive and affective trust-based mechanisms underlying the relationship between ethical leadership and organisational citizenship: A case of the head leading the heart? Journal of Business Ethics, 123(1), 113-123. https://doi.org/10.1007/ s10551-013-1803-2

Reich-Graefe, R. (2014). Calculative trust: Oxymoron or tautology? Journal of Trust Research, 4(1), 66-82. https://doi.org/10.1080/ 21515581.2014.891322

Rodgers, W. (2009). Three primary trust pathways underlying ethical considerations. Journal of Business Ethics, 91(1), 83-93. https:// doi.org/10.1007/s10551-009-0069-1

Rousseau, D. M., Sitkin, S. B., Burt, R. S., \& Camerer, C. (1998). Not so different after all: A cross-discipline view of trust. Academy of Management Review, 23(3), 393-404. https://doi.org/10.5465/ amr.1998.926617

Ryan, L. V., \& Buchholtz, A. K. (2001). Trust, risk, and shareholder decision making: An investor perspective on corporate governance. Business Ethics Quarterly, 11(1), 177. https://doi.org/10. 2307/3857876

Schaubroeck, J. M., Peng, A. C., \& Hannah, S. T. (2013). Developing trust with peers and leaders: Impacts on organizational identification and performance during entry. Academy of Management Journal, 56(4), 1148-1168. https://doi.org/10.5465/amj.2011. 0358

Sheppard, B. H., \& Sherman, D. M. (1998). The grammars of trust- A model and general implications. Academy of Management Review, 23(3), 422-437.

Singh, J. J., Iglesias, O., \& Batista-Foguet, J. M. (2012). Does having an ethical brand matter? The influence of consumer perceived ethicality on trust, affect and loyalty. Journal of Business Ethics, 111(4), 541-549. https://doi.org/10.1007/s10551-012-1216-7

Trapp, N. L. (2011). Staff Attitudes to talking openly about ethical dilemmas-The role of business ethics conceptions and trust. Journal of Buiness Ethics, 103, 543-552.

Tsai, Y. H., Joe, S.-W., Lin, C.-P., Chiu, C.-K., \& Shen, K.-T. (2015). Exploring corporate citizenship and purchase intention: Mediating effects of brand trust and corporate identification. Business Ethics: A European Review, 24(4), 361-377. https://doi.org/10. 1111/beer. 12073

Van Maanen, J. (1979). The fact of fiction in organizational ethnography. Administrative Science Quarterly, 24(4), 539-550.

Williamson, O. E. (1993). Calculativeness, trust, and economic organization. Journal of Law and Economics, XXXVI, 453-486.

Publisher's Note Springer Nature remains neutral with regard to jurisdictional claims in published maps and institutional affiliations. 